\title{
Establishment of a novel cell-based assay for screening small molecule antagonists of human interleukin-6 receptor
}

\author{
Yang-yang $\mathrm{HE}^{1}$, Yu YAN ${ }^{1}$, Chang ZHANG ${ }^{2}$, Peng-yuan $\mathrm{LI}^{3}$, Ping $\mathrm{WU}^{1}$, Peng DU ${ }^{2}$, Da-di ZENG ${ }^{2}$, Jian-song FANG ${ }^{1}$, \\ Shuang WANG ${ }^{2, *}$, Guan-hua DU1, * \\ ${ }^{1}$ Beijing Key Laboratory of Drug Targets Identification and Drug Screening, Institute of Materia Medica, Chinese Academy of Medical \\ Sciences and Peking Union Medical College, Beijing 100050, China; ${ }^{2}$ Institute of Biotechnology, Chinese Academy of Military Medical \\ Sciences, Beijing 100071, China; ${ }^{3}$ Drug Manufacturing Room of Pharmaceutical Department, Henan Provincial People's Hospital, \\ Zhengzhou 450003, China
}

Aim: Blockade of interleukin-6 (IL-6) or its receptor (IL-6R) is effective in preventing the progression of autoimmune diseases, such as systemic lupus erythematosus and rheumatoid arthritis. In the present study, we established a novel cell-based assay for identifying small molecule IL-6R antagonists.

Methods: HEK293A cells were transfected with recombinant plasmids pTaglite-SNAP-IL6R and pABhFc-IL6 to obtain membranebound IL-6R and recombinant human IL-6 coupled with human Fc fragment (rhIL-6), respectively. A novel screening assay based on the interaction between IL-6R and rhIL-6 was established, optimized and validated. The stability of the assay was also assessed by calculating the $Z^{\prime}$-factor.

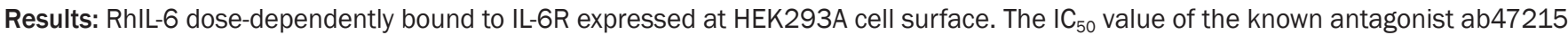
was $0.38 \pm 0.08 \mu \mathrm{g} / \mathrm{mL}$, which was consistent with that obtained using the traditional method $(0.36 \pm 0.14 \mu \mathrm{g} / \mathrm{mL})$. The value of $Z^{\prime}$-factor was 0.68 , suggesting that the novel assay was stable for high throughput screening. A total of 474 compounds were screened using the novel screening assay, and 3 compounds exhibited antagonistic activities $\left(\mathrm{IC}_{50}=8.73 \pm 0.28,32.32 \pm 9.08,57.83 \pm 4.24 \mu \mathrm{g} / \mathrm{mL}\right)$. Furthermore, the active compounds dose-dependently inhibited IL-6-induced proliferation of 7TD1 cells, and reduced IL-6-induced STAT3 phosphorylation in U937 cells.

Conclusion: A novel cell-based screening assay for identifying small molecule IL-6R antagonists was established, which simplifies the procedures in traditional cellular ELISA screening and profiling and reduces the costs.

Keywords: IL-6; IL-6 receptor; screening assay; high throughput screening; eukaryotic expression; cellular ELISA; autoimmune disease

Acta Pharmacologica Sinica (2014) 35: 1453-1462; doi: 10.1038/aps.2014.90; published online 27 Oct 2014

\section{Introduction}

Interleukin-6 (IL-6) is a key cytokine that was originally identified as a B-cell differentiation factor in 1985; it is a multifunctional moderator regulating acute phase reaction, immune response, inflammation, bone metabolism and hematopoiesis ${ }^{[1,2]}$. However, under some pathological conditions, continuous addition of IL-6 has been shown to increase autoantibodies, such as anti-double-stranded DNA (anti-dsDNA) antibody production, making significant contributions to the inflammatory response and accelerating the

\footnotetext{
* To whom correspondence should be addressed.

E-mail dugh@imm.ac.cn (Guan-hua DU); wangsshuang@gmail.com (Shuang WANG)

Received 2014-05-07 Accepted 2014-07-18
}

progression of autoimmune diseases such as systemic lupus erythematosus (SLE) and rheumatoid arthritis (RA) ${ }^{[3-5]}$. A blockade of IL-6 or its receptor has been demonstrated to prevent elevated anti-dsDNA antibody levels and the progression of autoimmune diseases in addition to improving survival rates $^{[6]}$.

Tocilizumab, a humanized monoclonal antibody (mAb) against the a-chain of the IL-6 receptor (IL-6Ra, also known as IL-6R), prevents the binding of IL-6 to membrane-bound IL-6 $R^{[7]}$. The safety and efficacy of tocilizumab has been assessed in many clinical trials in patients with RA, SLE, juvenile idiopathic arthritis, and Castleman's disease ${ }^{[8-10]}$. However, therapeutic mAbs are usually produced from nonhuman cell lines, and consequently, the exogenous biomacromolecules theoretically can invoke anti-globulin responses in 
some patients ${ }^{[11,12]}$. Therefore, it may be a reasonable strategy to develop small molecule drugs against IL-6R in the patients with anti-globulin responses to therapeutic mAbs. However, there are currently no small molecule drugs in clinical use or in late clinical trials that specifically target human IL-6R. For these reasons, research and development of novel IL-6R antagonists with a higher efficacy and less side effects should be of significance in clinical applications.

With a focus on drug discovery, various assays for identifying IL-6R antagonists have been developed during the past several years, which have significantly improved screening efficiencies. A classical cell-based assay, the 7TD1 cell model, was established by Van Snick in 1986; this assay used an IL-6 dependent mouse-mouse hybrid cell proliferation model to determine the blocking effects of compounds ${ }^{[13]}$. It is an effective method for identifying human IL-6R antagonists and is widely used in targeted drug discovery and fundamental research $^{[14,15]}$. However, its long testing cycle (often 3-4 d) for a proliferation inhibition experiment may be a weakness to rapid screening, and the detection index (cell survival rate) itself seems to incapably rule out false positives resulting from drug toxicity.

With the innovation of the polymerase chain reaction (PCR) technique and optimization of the Escherichia coli expression system, a screening assay based on phage display technology for identifying IL-6R antagonists was established and applied in the recent past ${ }^{[16,17]}$. It is a burgeoning and efficient screening technique, particularly for identifying candidates with a high affinity. Moreover, the emergence of fully synthetic human phage surface display technology opens up a new method for reducing immunogenicity ${ }^{[18,19]}$. However, there is no doubt that a micro-molecule polypeptide library or a miniaturization antibody library is required; consequently, the novel screening assay based on phage display technology is merely used for discovering specified types, such as polypeptide drugs, antibodies and other biological agents.

Some methods derived from soluble receptor-ligand binding assays are also widely used in screening IL-6R antagonists ${ }^{[20,21]}$. However, each of the assays seemingly has pros and cons. For example, the radioactive ligand-receptor binding test is considered to be an effective, sensitive, and classical analysis method, but safer methodologies than radiolabeled assays allow the use of radioactivity to be avoided ${ }^{[22]}$. A safe method based on the receptor-ligand binding assay mechanism is the enzyme-linked immunosorbent assay (ELISA); this is a quick, simple and extensive approach ${ }^{[21,23]}$. However, the ELISA still has room for improvement. For example, it has not yet been addressed whether the operation steps can be simplified without influencing detection sensitivity or whether the binding process of the receptor and its ligand could be similar to the process of the natural membrane-bound receptor binding to its ligand.

Therefore, developing novel, effective and ingenious assays for identifying IL-6R antagonists may provide opportunities to screen for discovering potent, effective antagonists. We report herein an innovative, cell-based screening assay for identifying IL-6R antagonists by using two new forms of proteins: human membrane IL-6R, located on the HEK293A cell surface, and recombinant human IL-6 (rhIL-6) coupled with the human Fc fragment.

\section{Materials and methods \\ Materials and instrumentation}

The human IL-6 and IL-6Ra genes were purchased from Origene Technologies. The HEK293A cells, 7TD1 cells and U937 cells were obtained from the Cell Bank of the Chinese Academy of Sciences (Shanghai, China). The expression plasmid pTaglite-SNAP was purchased from Cisbio Bioassays Corporation. The competent Escherichia coli cells Top10 were purchased from TransGen Biotech Corporation (Beijing, China). Restriction enzymes, such as Not I and Xba I, were purchased from New England Biolabs. Thermus aquaticus DNA polymerase and T4 DNA ligase were purchased from Takara Biotech (Dalian, China). RPMI-1640 culture medium, a-MEM culture medium and fetal bovine serum (FBS) were purchased from Gibco Life Technologies. The transfection reagent Lipofectamine 2000 system was purchased from Invitrogen Corporation. A total of 474 small molecular compounds that belonged to our in-house library were provided by the National Center for Drug Screening, Institute of Materia Medica, Chinese Academy of Medical Sciences, and each of the compounds was stored in DMSO and had an initial concentration of $10 \mathrm{mg} / \mathrm{mL}$. The microplate reader, SpectraMax M5, was purchased from BD Biosciences. The nucleus dye 4',6-diamidino-2-phenylindole (DAPI) was purchased from Partec Flow Cytometry Technology (Görlitz, Germany). The cellomics arrayscan VTI HCS reader was purchased from Thermo Scientific. The cell counting kit-8 (CCK-8) system was purchased from Dojindo Molecular Technologies Inc (Kyushu, Japan). The Gel Doc ${ }^{\mathrm{TM}} \mathrm{XR}+$ system and the Quantity One 1-D analysis software were purchased from Bio-Rad Laboratories. All of the manufacturers' materials and instrumentations described above were obtained from the USA unless otherwise specified. The primary antibodies and secondary antibodies used in this study and their working concentrations are listed in Table 1, and the DNA primers designed and used in this study are listed in Table 2.

\section{Constructions of the recombinant eukaryotic expression plasmids}

The full length of the human IL-6Ra chain gene and the IL-6 gene were amplified by PCR using the specific primers listed in Table 2. Using the instrumental enzymes of the gene engineering mentioned above, the DNA products were reconstructed separately in plasmid pTaglite-SNAP, which is a commercialized vector expressing the receptor of interest at the cell surface, and in plasmid pABhFc, which is used to express secretory IL- 6 coupling with the human FC fragment at the C-terminus ${ }^{[24,25]}$. The recombinants, pTaglite-SNAP-IL6R and pABhFc-IL6, were analyzed and identified by restriction 
Table 1. Antibodies used in this study.

\begin{tabular}{lll}
\hline \multicolumn{1}{c}{ Antibody } & \multicolumn{1}{c}{ Dilution } & Source \\
\hline Rabbit anti-human IL-6R polyclone antibody (\#Sc-13947) & $1: 100$ (for IF); 1:1000 (for WB) & Santa Cruz Biotechnology \\
Goat anti-human IgG (H+L) (HRP conjugate, \#ZB-2304) & $1: 2000$ & ZhongShan Golden Bridge Bio \\
Specific anti-IL6R antagonist antibody (\#ab47215) & Gradient dilution & Abcam \\
Phospho-stat3 (Tyr705) (D3A7) XP ${ }^{\circledR}$ rabbit mAb (\#9145) & $1: 2000$ & Cell Signaling Technology (CST) \\
Anti-rabbit lgG (H+L), F(ab') 2 fragment (Alexa Fluor ${ }^{\circledR} 488$ conjugate) & $1: 1000$ & CST \\
Anti-rabbit lgG (HRP conjugate) & $1: 2000$ & CST \\
B-Actin (13E5) rabbit mAb & $1: 4000$ & CST \\
Stat3 (124H6) mouse mAb (\#9139) & $1: 2000$ & CST \\
\hline
\end{tabular}

IF, immunofluorescence assay; WB, Western blot assay.

Table 2. DNA primers designed and used in this study.

\begin{tabular}{clcc}
\hline Name & Sequence $\left(5^{\prime} \rightarrow 3^{\prime}\right)$ & Tm value $\left({ }^{\circ} \mathrm{C}\right)$ & Restriction site \\
\hline p-IL6-F & AGTGAATTCGCCGCCACCATGAACTCCTTCTCCACAAGC & 61 & EcoR I \\
p-IL6-R & TGAGCTAGCCATTTGCCGAGAGCCC & 63 & Nhe I \\
p-IL6R-F & AATGCGGCCGCATGCTGGCCCCAAGGC & 58 & Not I \\
p-IL6R-R & GGTTCTAGAGGGCTATCTGGGGAAGAAGTAGTC & 55 & Xba I \\
\hline
\end{tabular}

Base sequences underlined were the sites for restriction digestion; F and R separately referred to forward primer and reverse primer.

enzyme digestion and a sequencing analysis.

\section{Cell culture and treatment}

The HEK293A cells were maintained in a-MEM medium supplemented with $10 \%$ heat-inactivated FBS in a $37^{\circ} \mathrm{C}$ incubator with $5 \% \mathrm{CO}_{2}$. For all the experiments, the cells were grown to an $80 \%$ confluence with no more than 20 passages. The cells were transfected separately by the expression plasmids pTaglite-SNAP-IL6R and pABhFc-IL6 using the transfection reagent Lipofectamine 2000 system according to the manufacturer's instructions.

The 7TD1 cells were maintained in RPMI-1640 medium supplemented with 10\% heat-inactivated FBS and rhIL-6 (4 $\mathrm{ng} / \mathrm{mL}$ ) in a $37^{\circ} \mathrm{C}$ incubator with $5 \% \mathrm{CO}_{2}$. For the proliferation inhibition test, the cells were washed three times to remove the growth factor IL-6 and were inoculated in 96-well plates. After being pre-incubated with or without the test compounds for $1 \mathrm{~h}$, the cells were exposed in the presence or absence of different concentrations of rhIL-6 (or IL-6). The number of viable cells was counted by an automated cell counter every $12 \mathrm{~h}$ over $3 \mathrm{~d}$. After $72 \mathrm{~h}$, the viabilities of the 7TD1 cells were measured by the CCK-8 system ${ }^{[26]}$.

The U937 cells were maintained in RPMI-1640 medium supplemented with $10 \%$ heat-inactivated FBS in a $37^{\circ} \mathrm{C}$ incubator with $5 \% \mathrm{CO}_{2}$.

\section{Immunofluorescence assay}

The expression level of IL-6R was examined by an indirect immunofluorescence assay using a rabbit anti-human IL-6Ra polyclone antibody and its corresponding secondary antibody.
Briefly, the HEK293A cells transfected by the gene pTagliteSNAP-IL6R for $36 \mathrm{~h}$ were washed, fixed with $4 \%$ paraformaldehyde for $30 \mathrm{~min}$ at room temperature (RT), and blocked with $2 \%$ BSA for $1 \mathrm{~h}$ at $37^{\circ} \mathrm{C}$. Next, the cells were incubated with the primary antibody mentioned above for $1 \mathrm{~h}$ at $37^{\circ} \mathrm{C}$, followed by the Alexa Fluor ${ }^{\circledR} 488$-conjugated secondary antibody. Finally, after being washed, the cells were incubated in DAPI solution for $5 \mathrm{~min}$ at RT in the dark. Live cell imaging was simultaneously viewed using a Cellomics arrayscan VTI HCS reader at an excitation wavelength of $355 \mathrm{~nm}$ for DAPI and $495 \mathrm{~nm}$ for Alexa Fluor ${ }^{\circledR} 488$.

\section{Western blotting assay}

The expression level of IL-6R was quantified by a Western blot assay. After transfection with the gene pTaglite-SNAP-IL6R, the HEK293A cells were collected, and the total protein was extracted in lysis buffer as described by Schreiber et al ${ }^{[27]}$. A total of $20 \mu \mathrm{g}$ of protein extract was resolved on a 10\% SDSPAGE gel, transferred onto a polyvinylidene fluoride membrane, and blocked with 5\% BSA in Tris-buffered saline (TBS) for $1 \mathrm{~h}$ at $37^{\circ} \mathrm{C}$. The membrane was washed three times in TBS with $0.1 \%$ Tween 20 (TBS-T) and incubated with the antiIL6Ra polyclone antibody at $4{ }^{\circ} \mathrm{C}$ overnight. The membrane was washed three times in TBS-T for $10 \mathrm{~min}$ and incubated with anti-rabbit IgG (HRP conjugate) in TBS. After another three washes with TBS-T for $10 \mathrm{~min}$, the membrane was reacted with an enhanced chemiluminescence system for a moment and was then exposed to films. The expression level of IL-6R was quantified by scanning densitometry using a Quantity One 1-D analysis system. 
The levels of the protein signal transducer and the activator of transcription 3 (STAT3) phosphorylation were also quantified by a Western blot assay. The U937 cells were preincubated with or without the test compounds for $1 \mathrm{~h}$ and were then stimulated by rhIL-6 (or IL-6) for $30 \mathrm{~min}$ in a $37^{\circ} \mathrm{C}$ incubator with $5 \% \mathrm{CO}_{2}$. The following procedures for the Western blot assay are similar to those described above except for the primary antibody involved.

\section{Purification of rhlL-6}

After transfection with the plasmid pABhFc-IL6 for $72 \mathrm{~h}$, the HEK293A cell culture supernatants were collected and filtered with a $0.45-\mu \mathrm{m}$ filter membrane. Next, the rhIL-6 in the supernatants was purified by the protein A chromatography method described by $\mathrm{Ng}$ et al ${ }^{[28]}$. The molecular weight and purity of the purified products were detected by $10 \%$ SDSPAGE.

\section{Cellular ELISA}

The direct binding capacity of rhIL-6 coupled with human Fc and the secondary antibody (HRP conjugate) was investigated. Each well of a high-binding 96-microwell plate was coated with different concentrations of rhIL-6 (or bevacizumab or ab47215) for $1 \mathrm{~h}$ at $37^{\circ} \mathrm{C}$. The plate was blocked with $2 \%$ BSA for $1 \mathrm{~h}$ at $37^{\circ} \mathrm{C}$; then, anti-human IgG goat $\mathrm{mAb}$ (HRP conjugate) was added to each well. After three washes with PBS, a colorimetric assay format was followed as described by Emon et a ${ }^{[29]}$. The absorbance of each well was determined in a dualwavelength manner $(492-630 \mathrm{~nm})$ using an ELISA reader (Microplate Reader SpectraMax M5).

The binding capacity of rhIL-6 coupled with human Fc and the membrane receptor was investigated. After transfection with plasmid pTaglite-SNAP-IL6R for $36 \mathrm{~h}$, the HEK293A cells in each well were washed and fixed with $4 \%$ paraformaldehyde for $30 \mathrm{~min}$ at RT and blocked with $2 \%$ BSA for $1 \mathrm{~h}$ at $37^{\circ} \mathrm{C}$. Next, different concentrations of rhIL-6 were added to the wells, followed by incubation for $1 \mathrm{~h}$ at RT. The cells were washed three times to remove the dissociative rhIL-6. The following procedures for the ELISA were similar to those described in the previous paragraph.

Some potential factors, such as temperature states and blocking systems, which may influence the binding capacity of rhIL- 6 and the membrane receptor, were investigated by the cellular ELISA as described above.

\section{Determination of the Z'-factor}

The $Z^{\prime}$-factor was determined to evaluate the stability and suitability of the method in a 96-well format by three separate experiments. To calculate the $Z^{\prime}$-factor of the assay, the rhIL-6 reactions (containing 2\% BSA) were assayed in 25 nonmarginal wells of a plate; another 25 non-marginal wells of the plate were used for background controls (containing only $2 \%$ BSA, assuming that rhIL- 6 was neutralized by the antagonists). Throughout the cell culture assays and cellular ELISA that followed, the same medium or PBS was added to all marginal wells to reduce the errors. The $Z^{\prime}$-factor for the assay was calculated as described by Zhang et al ${ }^{[30]}$.

\section{Verification of the modified screening assay}

A known antagonist, ab47215, was used to assess the reliability of the modified assay ${ }^{[31,32]}$. Different concentrations of ab47215 were added to the rhIL- 6 reactions and incubated together with membrane IL-6R for $1 \mathrm{~h}$ at $37^{\circ} \mathrm{C}$. After three washes with PBS, a secondary antibody was used to detect the rhIL-6 that was bound to membrane IL-6R as described above. To calculate the block rate (inhibition rate), the mathematical equation was used:

Inhibition rate $=$

$$
\left(O D_{\text {rhIL-6 alone }}-O D_{\text {antagonist+rhIL6 }}\right) / O D_{\text {rhIL-6 alone }} \times 100 \%
$$

\section{Preliminary screening and verification of active compounds}

A total of 474 compounds from the small molecular compound library were added separately to the rhIL-6 reactions (the final concentration of each compound was $0.1 \mathrm{mg} / \mathrm{mL}$ ) for primary screening by the cell-based assay. The positive compounds were re-screened in a secondary screening to test and verify the results.

A previous model described by Vardanyan et al ${ }^{[21]}$ was used to examine the functions of the active compounds obtained by the preliminary screening and thus to assess the reliability of the novel assay (several negative compounds in the preliminary screening were included as a control). The procedure is as follows: the plates were coated with soluble IL-6R overnight at $4^{\circ} \mathrm{C}$ and pre-blocked with $1 \%$ BSA at RT for $1 \mathrm{~h}$. After three washes, the wells were incubated with human IL-6 plus one of eight concentrations of the compounds at RT for $2 \mathrm{~h}$. After washing to remove any unbound IL-6, the wells were incubated with an anti-human IL-6 antibody (primary antibody) at $37^{\circ} \mathrm{C}$ for $1 \mathrm{~h}$, and washed and incubated with a secondary antibody (HRP conjugate) at $37^{\circ} \mathrm{C}$ for $30 \mathrm{~min}$. The $\mathrm{IC}_{50}$ of each active compound was calculated using Eq (1) described above.

\section{Statistical analysis}

The results are expressed as the mean \pm SEM of at least three independent experiments. The statistical significance was assessed by Student's $t$-test for paired populations or a oneway ANOVA followed by an appropriate post hoc test. $P$ values $<0.05$ were considered statistically significant.

\section{Results}

Construction of the recombinant eukaryotic expression plasmids We initially amplified the IL-6Ra and IL-6 genes by PCR using two pairs of specific primers listed in Table 1 . One percent agarose gel electrophoresis was used to detect the relative molecular weights of the amplification products. As shown in Figure 1A, the electrophoresis band analysis revealed that the DNA products were 1000-2000 base pairs (bp) in length and 500-750 bp in length, respectively, which was in agreement with the theoretical molecular weights of the IL-6Ra and IL-6 genes $^{[33,34]}$. Similarly, we detected the validities of the recom- 
A

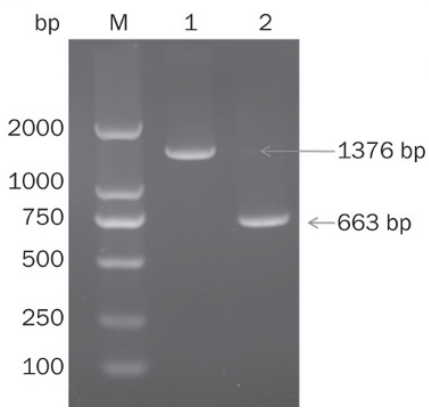

B

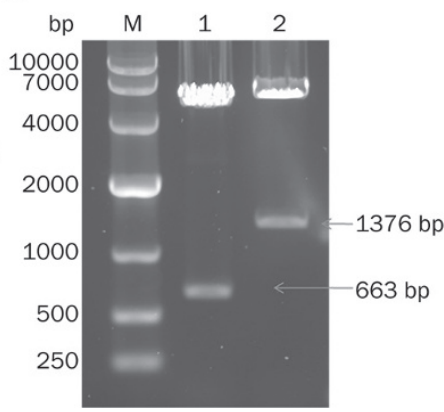

Figure 1. Constructions of the recombinant eukaryotic expression plasmids. (A) Electrophoretogram of the PCR products. M, low molecular weight DNA markers; 1, IL-6R $\alpha$ gene; 2 , IL-6 gene. The arrows separately indicate the theoretical molecular weights of the IL-6R $\alpha$ and IL- 6 genes (similarly hereinafter). (B) Electrophoretogram of the recombinant plasmids identified by the restriction enzyme digestion. $\mathrm{M}$, high molecular weight DNA markers; 1, plasmid pABhFc-IL6; 2, plasmid pTaglite-SNAPIL6R.

binant plasmids pTaglite-SNAP-IL6R and pABhFc-IL6 with an electrophoresis analysis after the accomplishment of gene recombination (Figure 1B). The results of this electrophoresis analysis and the DNA sequencing analysis (data not shown) confirmed that the human IL-6Ra-chain and IL-6 genes had been cloned correctly into the eukaryotic expression vectors.

\section{Expression of membrane IL-6R}

After transfection with pTaglite-SNAP-IL6R for $36 \mathrm{~h}$, the expression level of IL-6R was investigated by an immunofluorescence assay. As shown in Figure 2A, the transfected cell surface could emit a forceful green fluorescence, which suggested that plentiful receptors existed at the cell surface compared with the normal control group and the control plasmid group. The expression level of IL-6R was quantified by a Western blot assay which had a similar result as the immunofluorescence assay. Compared to normal cells and cells that were transfected by the control plasmid pTaglite-SNAP (blank load), the level of IL-6R significantly increased (Figure 2B). The results above demonstrated that IL-6R was successfully expressed and oriented at the HEK293A cell surface.

\section{Secretion expression and activity identification of rhIL-6}

The plasmid $\mathrm{pABhFc}$ was an engineering vector that was used for expressing secretory human IgG heavy chains that were constructed by our laboratory ${ }^{[19,25]}$. Based on the characteristics of the plasmid, we obtained soluble recombinant IL-6, which is a homodimer protein (purity $>90 \%$ by SDS-PAGE), as shown in Figure 3A. After the disulfide bond was broken by reduction loading buffer, rhIL-6 assumed a monomer form with a $50 \mathrm{kDa}$ relative molecular weight, which was consistent with the expected results.

To assess the functions of rhIL-6, we investigated its biological activity using the 7TD1 cell line, which is an IL6-dependent mouse cell. The number of 7TD1 cells ceased to increase at
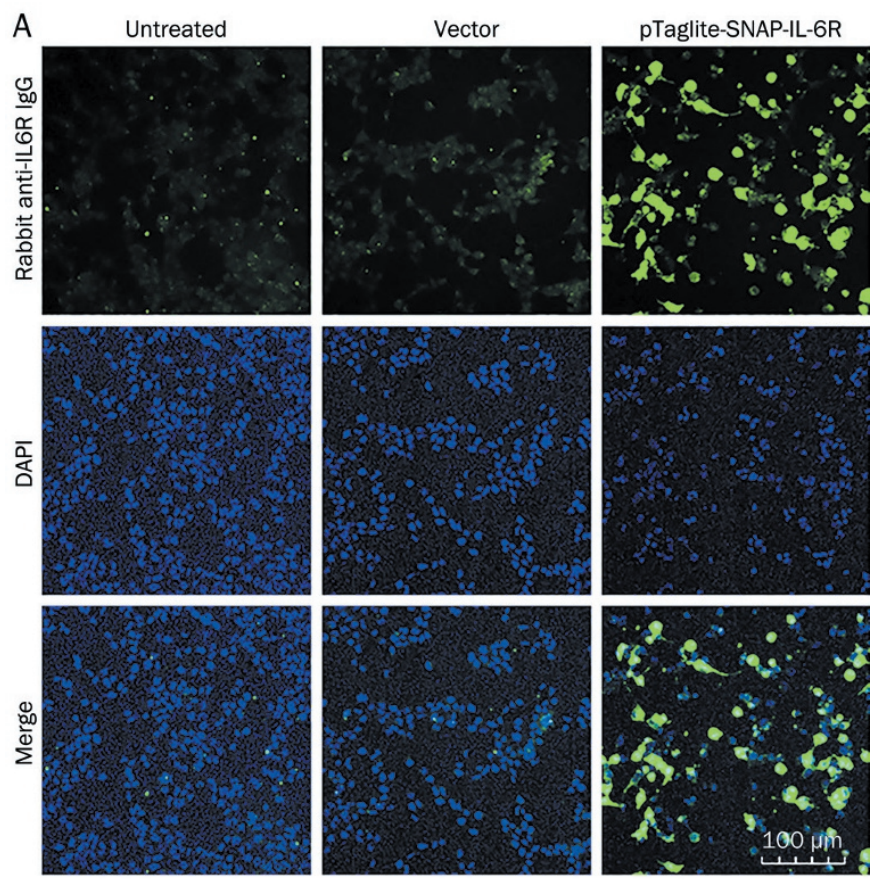

B
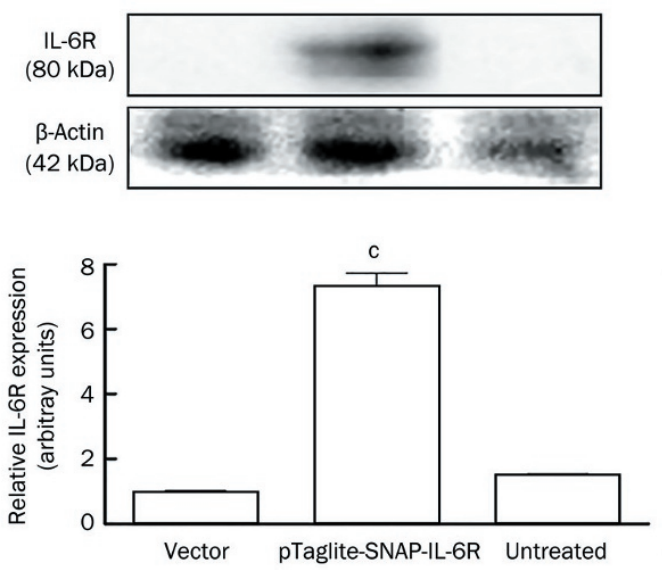

Figure 2. Identification and quantification of the expression level of IL6R. (A) Indirect immunofluorescence assay for identification. The images, from top to bottom, represent the IL-6R protein, nucleus and merged images with the IL-6R protein and nucleus. IL-6R was detected by Alexa Fluor $^{\circledR} 488$-labeled immunostaining (Green. Exposure time, $0.08 \mathrm{~s}$ ); the nuclei were stained by DAPI (Blue. Exposure time, $0.02 \mathrm{~s}$ ). Scale bar, 100 $\mu \mathrm{m}$. Camera, ORCA-R2 in the Cellomics arrayscan VTI HCS reader system. (B) The Western blot assay for the quantitative analysis. The bands for IL-6R were normalized to $\beta$-actin. The data represent the mean \pm SEM from three separate experiments. ${ }^{c} P<0.01$, significant compared with the control group (untreated) and the control plasmid pTaglite-SNAP group (blank load).

$36 \mathrm{~h}$ in the absence of rhIL-6. However, the number of 7TD1 cells in the presence of rhIL-6 (even at a low concentration of $1 \mathrm{ng} / \mathrm{mL}$ ) continuously increased until the nutrients were depleted at $72 \mathrm{~h}$ (Figure 3B). The results of the CCK-8 assay showed that cell viability declined in a dose-dependent man- 
A

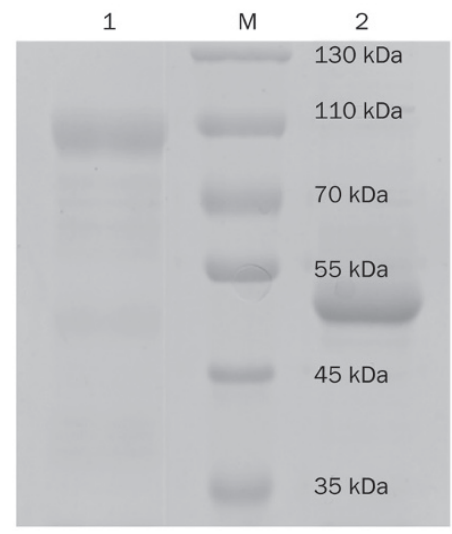

C

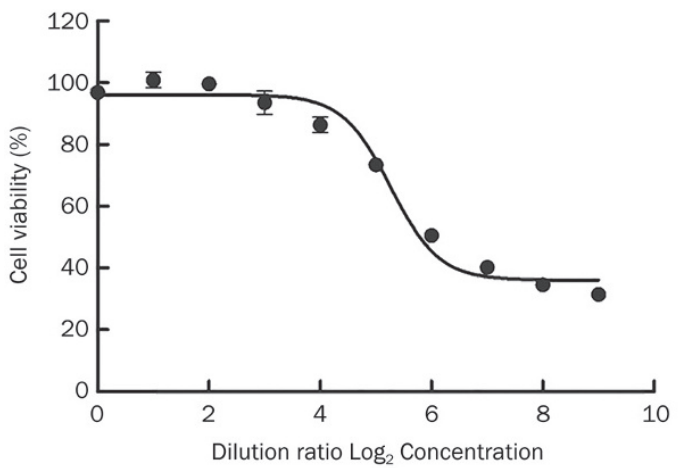

B

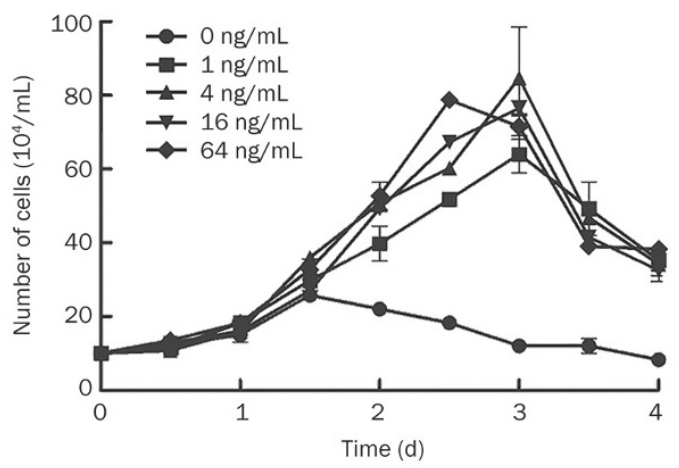

D
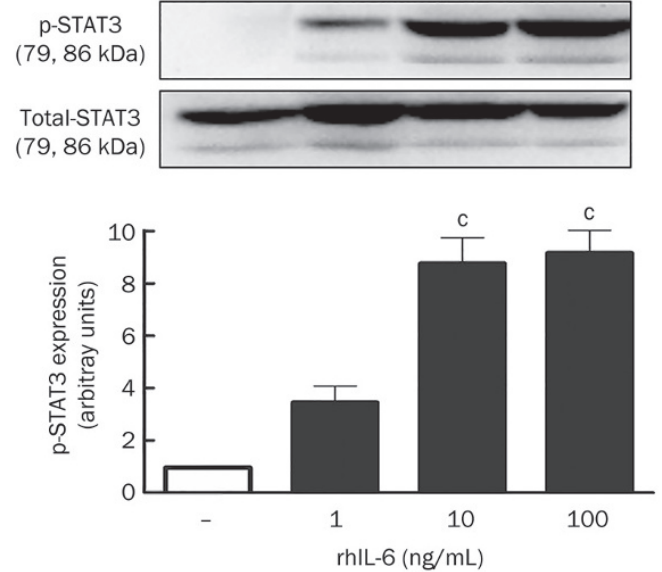

Figure 3. Expression and functional identification of rhIL-6 obtained from the transfected HEK293A cells. (A) SDS-PAGE analysis for the secretion of rhIL-6. M, protein markers; 1 , non-reductive form of rhIL-6; 2, reductive form of rhIL-6 (loading buffer containing $5 \%$-mercaptoethanol). (B) The 7TD1 cell number changed over time in the mediums with different concentrations of rhIL-6. The data represent the mean \pm SEM from five separate experiments. (C) The 7TD1 cell viabilities declined, accompanied by multiple proportional dilutions of rhIL-6 (the initial concentration of rhIL-6 was $20 \mathrm{ng} / \mathrm{mL}$ ). The data represent the mean \pm SEM from four separate experiments. (D) The Western blot assay for the quantitative analysis of protein phosphorylation of the JAK/STAT3 signal pathway mediated by rhIL-6 in the U937 cells. The bands for p-STAT3 were normalized to total-STAT3. The data represent the mean \pm SEM from four separate experiments. ${ }^{c} P<0.01$, significant compared with the untreated control.

ner with decreasing concentrations of rhIL-6 (Figure 3C), which was in agreement with that of the above cell number count analysis.

After being stimulated by different concentrations of rhIL-6 for $30 \mathrm{~min}$, the level of protein STAT3 phosphorylation in human U937 cells significantly increased compared to the control group (Figure 3D). Phosphorylated STAT3 (p-STAT3) is a crucial signal molecule in the JAK/STAT signaling pathway that is mediated by IL- $6^{[35,36]}$. The binding of IL- 6 to membrane IL-6R induces phosphorylation of STAT3 at Y705 residues, and p-STAT3 dimerizes and translocates to the nucleus, where it binds to the promoter of target genes to regulate transcription $^{[35,37]}$. Our results here indicated that rhIL-6 was able to bind to natural human IL-6R and then mediate signal transduction.

All the findings using the 7TD1 and U937 cells above confirmed that the homodimer protein rhIL-6 coupled with the human Fc fragment showed a bioactivity similar to that of natural IL-6.

\section{Establishment of a screening assay based on a cellular ELISA}

We initially determined the usefulness of the Fc fragment of rhIL-6 by using a simple and easy ELISA. As shown in Figure $4 \mathrm{~A}$, the absorbance value increased with the rise of the concentrations of rhIL-6, indicating that rhIL- 6 could bind to antihuman IgG goat $\mathrm{mAb}$ in a dose-dependent manner, consistent with the positive control bevacizumab (a human IgG-targeted VEGF). However, the negative control ab47215, which was a mouse $\mathrm{mAb}$ that did not contain the human $\mathrm{Fc}_{\mathrm{c}}$ fragment, could not bind to the secondary antibody. These results provide a foundation for the establishment of a simple and convenient cellular ELISA.

Next, a preliminary screening assay based on the cellular ELISA was tentatively established after the HEK293A cells were transfected by plasmid pTaglite-SNAP-IL6R. The absorbance value increased with the increasing concentrations of rhIL-6 (Figure 4B), demonstrating that rhIL-6 could bind to IL-6R expressed at the HEK293A cell surface in a dosedependent manner. 

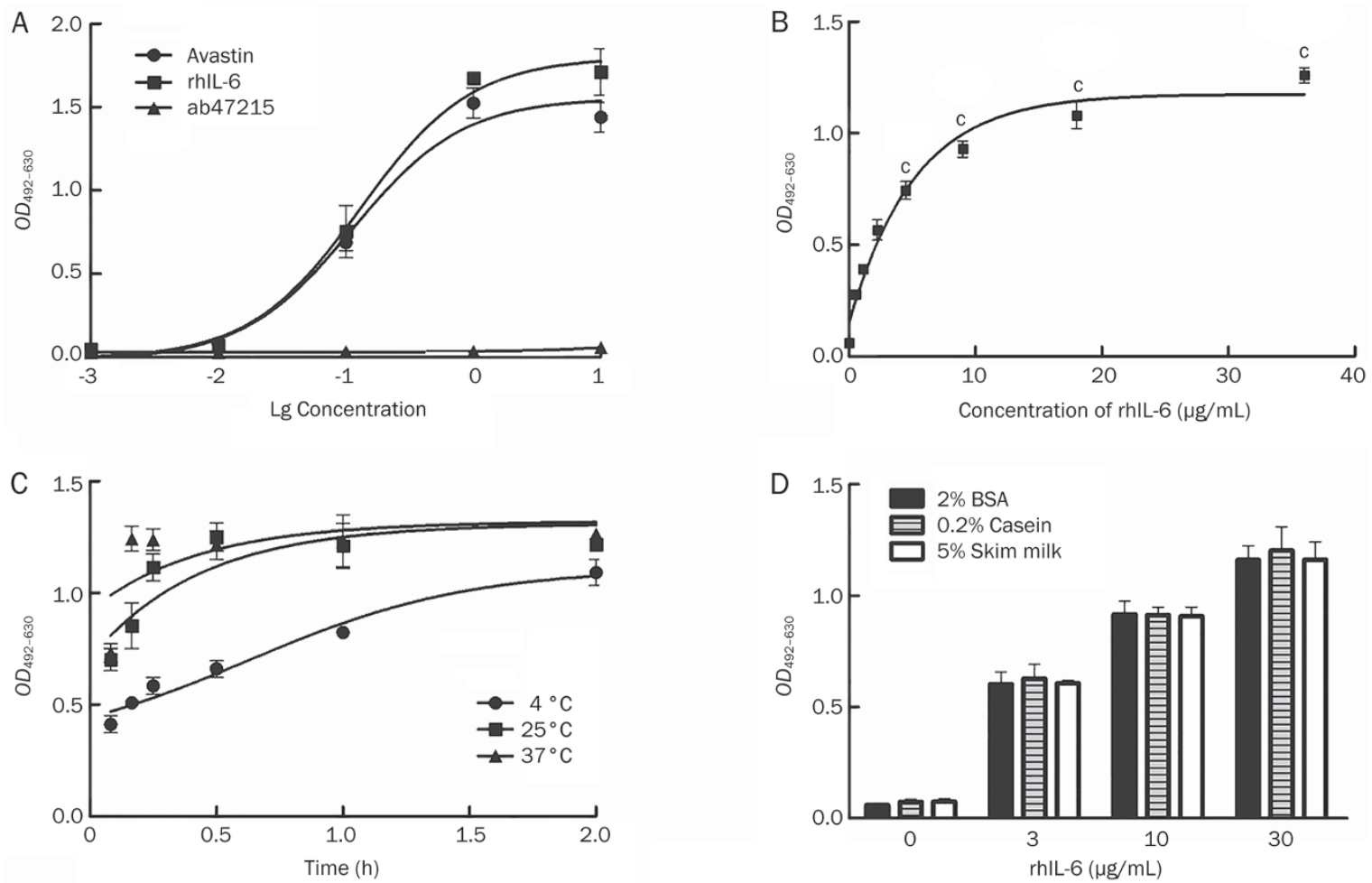

Figure 4. Establishment of a screening assay based on the cellular ELISA. (A) The binding capacity of rhlL-6 coupled with the Fc fragment and a secondary antibody (anti-human IgG goat mAb, HRP conjugate). $O D_{492-630}$ refers to the difference between the absorbance at a wavelength of $492 \mathrm{~nm}$ and the absorbance at a wavelength of $630 \mathrm{~nm}$ (similarly hereinafter). The data represent the mean \pm SEM from three separate experiments. (B) RhIL-6 was able to bind to IL-6R expressed at the HEK293A cell surface in a dose-dependent manner. The data represent the mean \pm SEM from five separate experiments. ${ }^{c} P<0.01$, significant compared with the PBS control group. ( $C$ and $D$ ) Effects of different temperature states and different blocking buffers on the binding capacity of rhlL-6 and its membrane-bound receptor.

Finally, some potential factors influencing the capacity of rhIL-6 binding to the membrane receptor were investigated. We found that the capacity showed significant differences in different temperature states (Figure 4C), and the number of rhIL-6 binding to membrane receptors reached saturation in the first $10 \mathrm{~min}$ at $37^{\circ} \mathrm{C}$, indicating that $37^{\circ} \mathrm{C}$ might be the optimum temperature for a rapid screening. Some common blocking systems for immunological tests, such as $2 \%$ BSA, $0.2 \%$ casein and $5 \%$ milk, seemingly had no obvious effect on the binding capacity (Figure 4D).

\section{Assessments of stability and reliability}

After optimizing these procedures, we determined the $Z^{\prime}$-factor of the assay and used a concentration of $10 \mu \mathrm{g} / \mathrm{mL}$ of rhIL-6 as a final concentration according to the results of Figure 4B. Under this circumstance, the wells coated with transfected cells presented intense absorbance values compared with the control wells, which were also coated with transfected cells but did not contain rhIL-6 (Figure 5A). Using a 96-well format, we were able to screen for IL-6R antagonists with a $Z^{\prime}$ factor of 0.68 .

The mouse antibody ab47215, which can competitively antagonize IL-6R, was used to evaluate the reliability of the assay. As shown in Figure 5B, ab47215 could block rhIL-6 from binding to its membrane receptor in a dose-dependent manner in this novel screening assay. The $\mathrm{IC}_{50}$ of ab47215 was $0.38 \pm 0.08 \mathrm{\mu g} / \mathrm{mL}$, which was consistent with that obtained from the traditional model $\left(\mathrm{IC}_{50}=0.36 \pm 0.14 \mu \mathrm{g} / \mathrm{mL}\right)$. In addition, Figure $5 \mathrm{~B}$ also shows a comparison of the assay with traditional assays in terms of maximum inhibitory rates converted from signal values. The maximum inhibitory rate in the new method was slightly lower than that in the traditional method at the same concentration of ab47215. These results demonstrated that our assay reported herein could identify known IL-6R antagonists.

\section{Application and evaluation of the novel assay}

A total of 474 compounds were screened at random, as shown in Figure 6A, and ten of those compounds showed some antagonistic activities against membrane IL-6R. After a secondary screening (re-screening, data not shown), the antagonistic activities of three active compounds were confirmed. The former two of the three have the same basic parent structure as 7-(methylsulfonyl)-4-oxo-3,4-dihydropyrazolo[5,1-d] $[1,2,3,5]$ tetrazine, and the latter compound is a derivative of tetrahydrofuro[3,2-c]naphtho[2,1-e]oxepine-1,3-dione.

The other model, which was used to evaluate the functions of the three active compounds and the reliability of the novel 

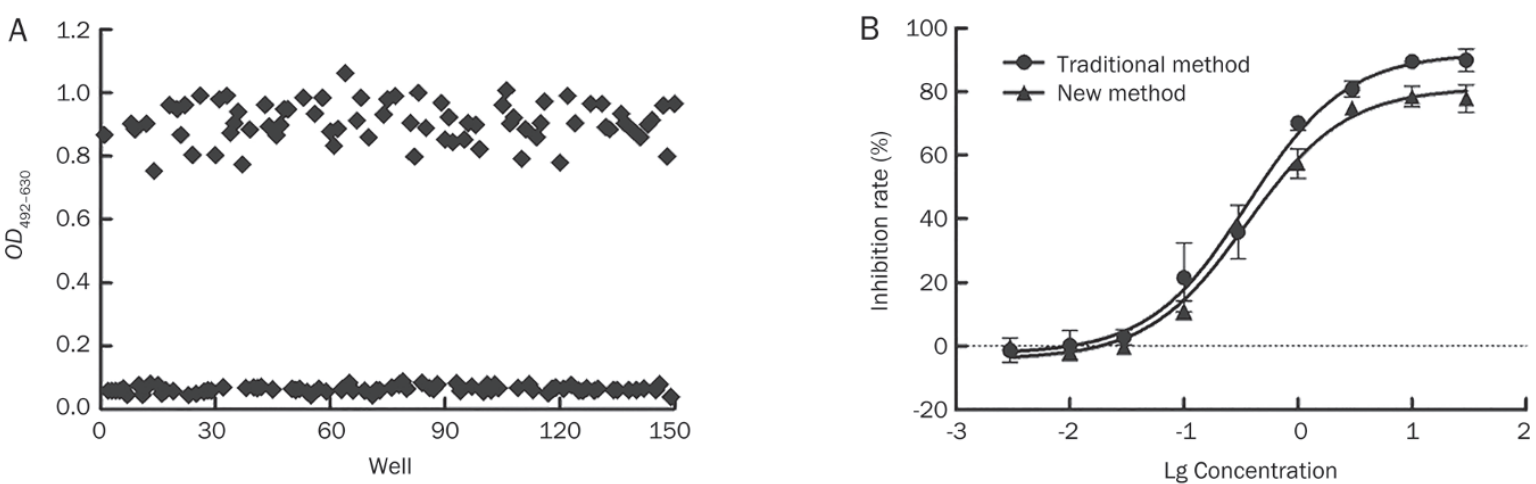

Figure 5. Stability and reliability assessments of the assay. (A) The assay was screened by three independent experiments in the presence (75 samples) and absence (75 samples) of rhIL-6 $(10 \mu \mathrm{g} / \mathrm{mL})$ at optimized conditions, and a Z'-factor of 0.68 was determined. (B) The competitive binding of ab47215 to membrane IL-6R expressed at the cell surface in the novel assay $\left(\mathrm{IC}_{50}=0.38 \pm 0.08 \mu \mathrm{g} / \mathrm{mL}\right)$ and soluble IL-6R in the traditional assay $\left(\mathrm{IC}_{50}=0.36 \pm 0.14 \mu \mathrm{g} / \mathrm{mL}\right)$. The $95 \%$ confidence intervals for the mean values were approximately 0.24 to $0.56 \mu \mathrm{g} / \mathrm{mL}$ and $0.27 \mathrm{to} 0.47 \mu \mathrm{g} / \mathrm{mL}$, respectively. The data represent the mean \pm SEM from three separate experiments.

assay, illuminated that the novel screening assay described in this study was reliable. As shown in Figure 6B, the active compounds were able to block soluble IL-6R from binding to its ligand in a dose-dependent manner. The $\mathrm{IC}_{50}$ of the compounds were $32.32 \pm 9.08,8.73 \pm 0.28$ and $57.83 \pm 4.24 \mu \mathrm{g} / \mathrm{mL}$, respectively. The $95 \%$ confidence intervals for the mean values were approximately 23.74 to $44.0,5.69$ to 13.38 and 42.79 to $78.16 \mu \mathrm{g} / \mathrm{mL}$, respectively. However, several negative compounds in the preliminary screening were unable to show obvious antagonistic activities (data not shown). In addition, further evaluation showed that the active compounds were able to inhibit the proliferation of the 7TD1 cells induced by IL-6 in a dose-dependent manner (Figure 6C) and reduced the phosphorylation level of STAT3 in the U937 cells induced by IL-6 (Figure 6D). These results demonstrated that the active compounds were antagonists against IL-6R, and the assay that we established was reliable for identifying IL-6R antagonists.

\section{Discussion}

In summary, an innovative cell-based screening assay was established by preparing two new forms of proteins, human membrane-bound IL-6R and rhIL-6 coupled with the human Fc fragment, which were obtained separately by transfecting two novel recombinant eukaryotic expression plasmids, pTaglite-SNAP-IL6R and pABhFc-IL6, into HEK293A cells. The assay was stable and reliable, which was evaluated by applying the $Z$ '-factor and confirmed by utilizing a known antagonist and an existing model. There were two advantages to this assay. First, the orientation expression of IL-6R at the HEK293A cell surface and the analogous expression patterns targeting IL-6R have not been reported. The natural membrane-bound IL-6R is now considered to play a key role in the physiological and pathological progress, and consequently, compared with the classical soluble receptor-ligand binding assay at the biochemical level, this novel assay that is conducted at the cell level might make the process of IL-6 binding to IL-6R expressed at the cell surface more similar to the natural binding process. Second, rhIL-6, which is a new form of recombinant protein coupled with the human Fc fragment, could directly bind to a secondary antibody, antihuman IgG goat mAb. However, the classical ELISA usually requires an anti-IL6 or IL-6R antibody as a primary antibody followed by a corresponding secondary antibody (for instance, HRP conjugate). The innovative fusion expression of rhIL-6 in the study played the function of the primary antibody and thus prevented the tedious process necessary in the ELISA without any obvious interference. It is well-known that commercial primary antibodies are expensive, especially under the conditions of large-scale use in high throughput screening. Therefore, the new assay in this study simplified the procedures and reduced costs compared with the classical cellular ELISA $^{[19]}$. Furthermore, based on the functional performance, rhIL-6 would be appropriate for the soluble IL-6R binding assay and would be able to simplify the steps. In conclusion, we established and applied an innovative cell-based screening assay for identifying IL-6R antagonists, which is a new and relatively easy method that provides a fresh strategy for other similar receptor-ligand binding assays.

\section{Acknowledgements}

This study was supported by the National Scientific \& Technological Major Project for "Significant New Drugs Creation" (№ 2012ZX09103-101-078) and the Special Foundation for Scientific Research in Public Health Industry (№ 200902008) and the Doctoral Innovation Foundation (№ 521005-31034). We are grateful to Dr Xiu-ying YANG (Chinese Academy of Medical Sciences \& Peking Union Medical College) for the introduction and the suggestion of constructing the plasmid pTaglite-SNAP-IL6R.

\section{Author contribution}

Yang-yang HE designed the experiments and drafted the manuscript; Yu YAN and Chang ZHANG carried out the cytological experiments, signaling studies and verification experiment 
A

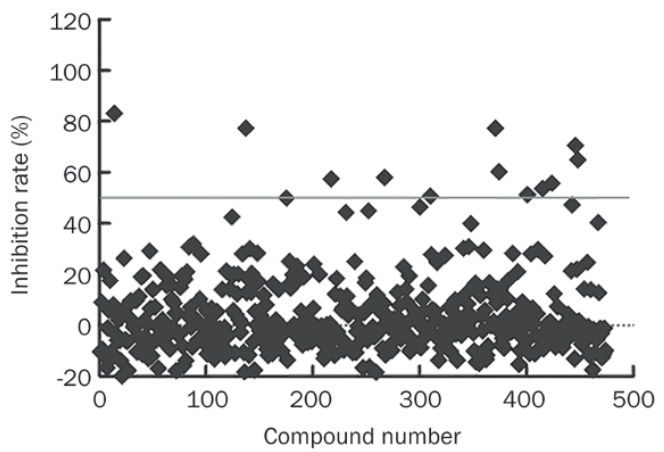

C

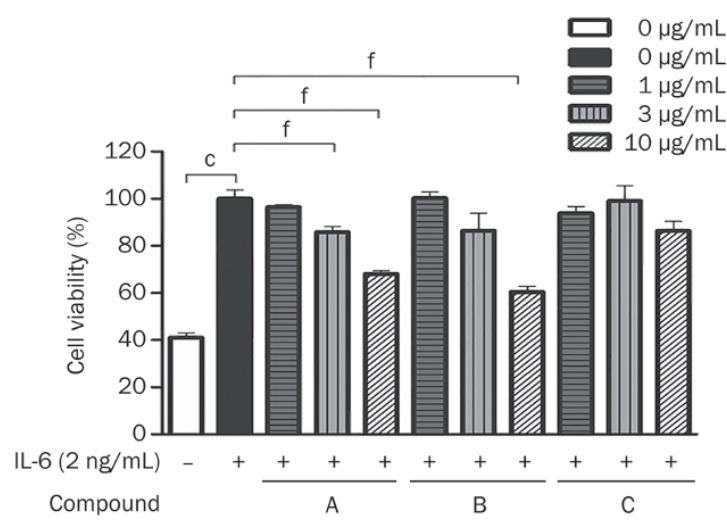

B

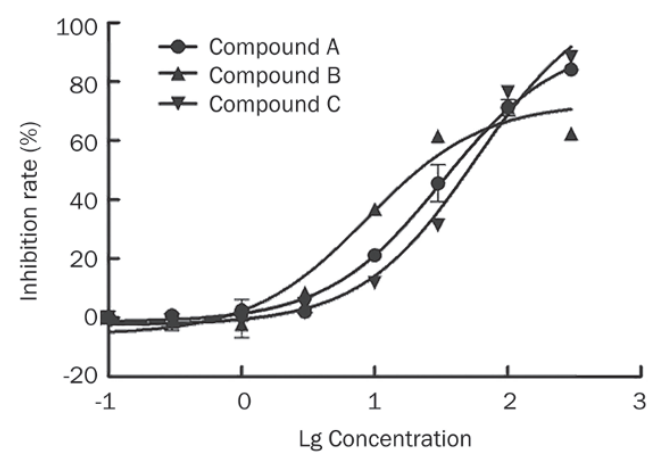

D
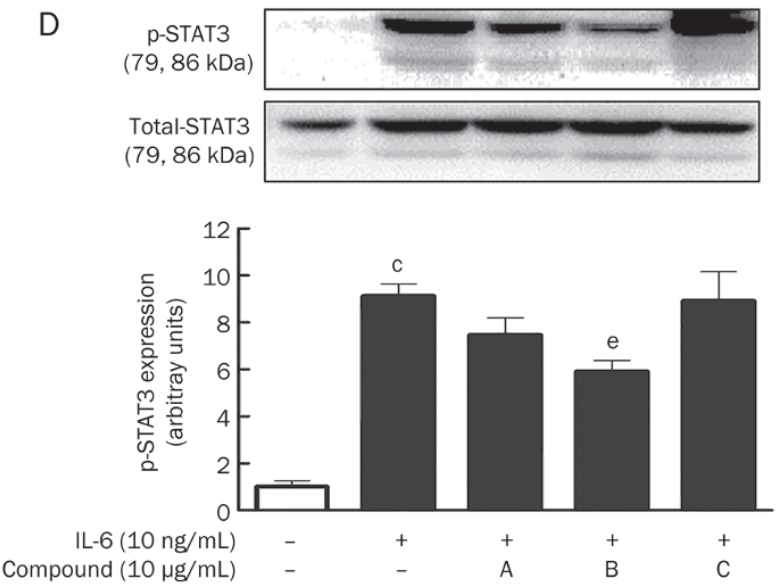

Figure 6. Preliminary screening using the novel cell-based assay established above and verification of the active compounds. (A) A total of 474 compounds in the small molecular compound library were screened, and of them, ten compounds (above line) demonstrated some antagonistic activities against membrane IL-6R. Each dot represents one compound. (B) The functional identification of the three active compounds selected using a widely used method based on the soluble receptor-ligand binding assay. Three compounds were able to block soluble IL-6R from binding to its ligand in a dose-dependent manner. The data represent the mean \pm SEM from five separate experiments. ( $C$ and $D)$ The compounds inhibited the proliferation of the 7TD1 cells (or the phosphorylation of STAT3 in the U937 cells) induced by IL-6. The data represent the mean \pm SEM from four independent experiments. ${ }^{\circ} P<0.01$, significant compared with the untreated control; ${ }^{\mathrm{e}} P<0.05,{ }^{\mathrm{f}} \mathrm{P}<0.01$, significant compared with IL-6 alone.

of the assay; Peng-yuan LI and Ping WU performed the studies of eukaryotic expression of the membrane receptor and its ligand; Peng DU participated in the purification of rhIL-6; Da-di ZENG and Jian-song FANG carried out the statistical analysis; Guan-hua DU and Shuang WANG performed the cellular ELISA, the evaluation of the assay, participated in the experimental design and drafted the manuscript.

\section{References}

1 Hirano T. Interleukin 6 (IL-6) and its receptor: their role in plasma cell neoplasias. Int J Cell Cloning 1991, 9; 166-84.

2 Mi XB, Zeng FQ. Hypomethylation of interleukin-4 and -6 promoters in T cells from systemic lupus erythematosus patients. Acta Pharmacol Sin 2008; 29: 105-12.

3 Pelliniemi TT, Irjala K, Mattila K, Pulkki K, Rajamaki A, Tienhaara A, et al. Immunoreactive interleukin- 6 and acute phase proteins as prognostic factors in multiple myeloma. Finnish Leukemia Group. Blood 1995; 85: 765-71.

4 Kishimoto T. The biology of interleukin-6. Blood 1989; 74: 1-10.

5 Wei ZF, Jiao XL, Wang T, Lu Q, Xia YF, Wang ZT, et al. Norisoboldine alleviates joint destruction in rats with adjuvant-induced arthritis by reducing RANKL, IL-6, $\mathrm{PGE}_{2}$, and MMP-13 expression. Acta Pharmacol Sin 2013; 34: 403-13.

6 Liang B, Gardner DB, Griswold DE, Bugelski PJ, Song XYR. Antiinterleukin-6 monoclonal antibody inhibits autoimmune responses in a murine model of systemic lupus erythematosus. Immunology 2006; 119: 296-305.

7 Nishimoto N, Kishimoto T. Humanized antihuman IL-6 receptor antibody, tocilizumab. Handb Exp Pharmacol 2008; 181: 151-60.

8 Straub RH, Härle P, Yamana S, Matsuda T, Takasugi K, Kishimoto T, et al. Anti-interleukin-6 receptor antibody therapy favors adrenal androgen secretion in patients with rheumatoid arthritis: A randomized, double-blind, placebo-controlled study. Arthritis Rheum 2006; 54: 1778-85.

9 Maeshima K, Ishii K, Torigoe M, Imada C, Iwakura M, Hamasaki H, et al. Successful tocilizumab and tacrolimus treatment in a patient with rheumatoid arthritis complicated by systemic lupus erythematosus. Lupus 2012; 21: 1003-6.

10 Bykerk VP, Ostör AJ, Alvaro-Gracia J, Pavelka K, Ivorra JA, Graninger $\mathrm{W}$, et al. Tocilizumab in patients with active rheumatoid arthritis and inadequate responses to DMARDs and/or TNF inhibitors: a large, open-label study close to clinical practice. Ann Rheum Dis 2012; 71: 1950-4. 
11 Isaacs JD. Antibody engineering to develop new antirheumatic therapies. Arthritis Res Ther 2009; 11: 225.

12 Zhao L, Ren TH, Wang DD. Clinical pharmacology considerations in biologics development. Acta Pharmacol Sin 2012; 33: 1339-47.

13 Van Snick J, Cayphas S, Vink A, Uyttenhove C, Coulie PG, Rubira MR, et al. Purification and $\mathrm{NH}_{2}$-terminal amino acid sequence of a T-cellderived lymphokine with growth factor activity for B-cell hybridomas. Proc Natl Acad Sci U S A 1986; 83: 9679-83.

14 Ward LD, Hammacher A, Zhang JG, Morton CJ, Simpson RJ, Weinstock $\mathrm{J}$, et al. Role of the C-terminus in the activity, conformation, and stability of interleukin-6. Protein Sci 1993; 2: 1472-81.

15 Hayashi M, Rho MC, Fukami A, Enomoto A, Nonaka S, Sekiguchi $\mathrm{Y}$, et al. Biological activity of a novel nonpeptide antagonist to the interleukin-6 receptor 20S, 21-epoxy-resibufogenin-3-formate. J Pharmacol Exp Ther 2002; 303: 104-9.

16 Naimuddin M, Kobayashi S, Tsutsui C, Machida M, Nemoto N, Sakai $\mathrm{T}$, et al. Directed evolution of a three-finger neurotoxin by using cDNA display yields antagonists as well as agonists of interleukin- 6 receptor signaling. Mol Brain 2011; 4: 1-16.

17 Yamaguchi J, Naimuddin M, Biyani M, Sasaki T, Machida M, Kubo T, et al. cDNA display: a novel screening method for functional disulfiderich peptides by solid-phase synthesis and stabilization of mRNAprotein fusions. Nucleic Acids Res 2009; 37: e108.

18 Huang JX, Bishop-Hurley SL, Cooper MA. Development of antiinfectives using phage display: biological agents against bacteria, viruses, and parasites. Antimicrob Agents Chemother 2012; 56 : 4569-82.

19 Yu R, Wang S, Yu YZ, Du WS, Yang F, Yu WY, et al. Neutralizing antibodies of botulinum neurotoxin serotype A screened from a fully synthetic human antibody phage display library. J Biomol Screen 2009; 14: 991-8.

20 Naruishi K, Takashiba S, Chou HH, Arai H, Nishimura F, Murayama Y. Role of soluble interleukin- 6 receptor in inflamed gingiva for binding of interleukin-6 to gingival fibroblasts. J Periodontal Res 1999; 34: 296-300.

21 Vardanyan M, Melemedjian OK, Price TJ, Ossipov MH, Lai J, Roberts $\mathrm{E}$, et al. Reversal of pancreatitis-induced pain by an orally available, small molecule interleukin-6 receptor antagonist. Pain 2010; 151: 257-65.

22 Weiergräber O, Schneider-Mergener J, Grötzinger J, Wollmer A, Küster $A$, Exner $M$, et al. Use of immobilized synthetic peptides for the identification of contact sites between human interleukin- 6 and its receptor. FEBS Lett 1996; 379: 122-6.

23 Ueda O, Tateishi H, Higuchi Y, Fujii E, Kato A, Kawase Y, et al. Novel genetically-humanized mouse model established to evaluate efficacy of therapeutic agents to human interleukin-6 receptor. Sci Rep 2013; 3: 1196.
24 Zwier JM, Roux T, Cottet M, Durroux T, Douzon S, Bdioui S, et al. A fluorescent ligand-binding alternative using Tag-lite ${ }^{\circledR}$ technology. J Biomol Screen 2010; 15: 1248-59.

25 Zhang C, Tang P, He Y, Du P, Sun ZW, Wang S, et al. Secretion expression of extracellular region of EGFR using mammalian cell and its identification. Lett Biotechnol 2012; 23: 635-9.

26 Dai Y, Chen J, Li H, Li S, Chen J, Ding Y, et al. Characterizing the effects of VPA, VC and RCCS on rabbit keratocytes onto decellularized bovine cornea. PLoS One 2012; 7: e50114.

27 Schreiber E, Harshman K, Kemler I, Malipiero U, Schaffner W, Fontana A. Astrocytes and glioblastoma cells express novel octamer-DNA binding proteins distinct from the ubiquitous Oct-1 and B cell type Oct-2 proteins. Nucleic Acids Res 1990; 18: 5495-503.

28 Ng CK, Osuna-Sanchez H, Valéry E, Sørensen E, Bracewell DG. Design of high productivity antibody capture by protein A chromatography using an integrated experimental and modeling approach. J Chromatogr B 2012; 899: 116-26.

29 Emon JMV, Chuang JC, Lordo RA, Schrock ME, Nichkova M, Gee SJ, et al. An enzyme-linked immunosorbent assay for the determination of dioxins in contaminated sediment and soil samples. Chemosphere 2008; 72: 95-103.

30 Zhang J, Chung TD, Oldenburg KR. Validation of high throughput screening assays. J Biomol Screen 1999; 4: 67-73.

31 Touboul C, Lis R, Al Farsi H, Raynaud CM, Warfa M, Althawadi H, et al. Mesenchymal stem cells enhance ovarian cancer cell infiltration through IL6 secretion in an amniochorionic membrane based 3D model. J Transl Med 2013; 11: 28.

32 Che Q, Liu BY, Liao Y, Zhang HJ, Yang TT, He YY, et al. Activation of a positive feedback loop involving IL- 6 and aromatase promotes intratumoral $17 \beta$-estradiol biosynthesis in endometrial carcinoma microenvironment. Int J Cancer 2014; 135: 282-94.

33 Yamasaki K, Taga T, Hirata Y, Yawata H, Kawanishi Y, Seed B, et al. Cloning and expression of the human interleukin-6 (BSF-2/IFN beta 2) receptor. Science 1988; 241: 825-8.

34 May LT, Shaw JE, Khanna AK, Zabriskie JB, Sehgal PB. Marked celltype-specific differences in glycosylation of human interleukin-6. Cytokine 1991; 3: 204-11.

35 Heinrich P, Behrmann I, Muller-Newen G, Schaper F, Graeve L. Interleukin-6-type cytokine signalling through the gp130/Jak/STAT pathway1. Biochem J 1998; 334: 297-314.

36 Liu DB, Hu GY, Long GX, Qiu H, Mei Q, Hu GQ. Celecoxib induces apoptosis and cell-cycle arrest in nasopharyngeal carcinoma cell lines via inhibition of STAT3 phosphorylation. Acta Pharmacol Sin 2012; 33: 682-90.

37 Jung JE, Kim GS, Chan PH. Neuroprotection by interleukin-6 is mediated by signal transducer and activator of transcription 3 and antioxidative signaling in ischemic stroke. Stroke 2011; 42: 3574-9. 